\title{
Reklasifikasi Peta Penutupan Lahan untuk Meningkatkan Akurasi Kerentanan Lahan
}

\section{Endang Savitri}

Balai Penelitian dan Pengembangan Teknologi Pengelolaan Daerah Aliran Sungai Solo Indonesia

\section{Irfan Budi Pramono ${ }^{1}$}

Balai Penelitian dan Pengembangan Teknologi Pengelolaan Daerah Aliran Sungai Solo Indonesia

Artikel Masuk : 23 Februari 2017

Artikel Diterima : 26 Maret 2017

Tersedia Online : 29 Agustus 2017

\begin{abstract}
Abstrak: Informasi mengenai kerentanan lahan suatu tempat dapat digunakan untuk merencanakan rehabilitasi pada lahan tersebut karena kerentanan lahan mencerminkan kepekaan lahan tersebut terhadap erosi. Kerentanan lahan ditentukan oleh beberapa faktor, yaitu kelerengan, jenis tanah, hujan, dan penutupan lahan. Di antara faktor-faktor tersebut yang dapat dikelola untuk menjaga kerentanan lahan adalah penutupan lahan. Kesalahan dalam klasifikasi penutupan lahan dapat menghasilkan kerentanan lahan yang berbeda, sehingga dapat menimbulkan kesalahan dalam penyusunan rencana sampai pelaksanaan rehabilitasi lahan. Tujuan penelitian ini adalah menyesuaikan klasifikasi peta penutupan lahan yang sudah ada agar dapat mendeteksi kerentanan lahan. Analisis dilakukan dengan cara membandingkan klasifikasi peta penutupan lahan saat ini dengan kriteria penutupan lahan untuk analisis kerentanan lahan. Hasil klasifikasi ditumpangsusunkan dengan peta sistem lahan yang kemudian dapat ditentukan kerentanannya. Hasil penelitian di DAS Cisadane menunjukkan bahwa kekurangtelitian dalam menentukan penutupan lahan pertanian lahan kering menjadi semak belukar atau tegal/tanah terbuka dapat mengakibatkan kelas rentan bergeser menjadi sangat rentan. Perbedaan penentuan hutan tanaman dan perkebunan yang masih belum ditanami dengan tegalan/tanah terbuka juga dapat memperluas kerentanan lahan sebesar 12,3\%. Permukiman di perkotaan yang berubah menjadi gedung dapat menurunkan tingkat kerentanan lahan sebesar 2,1\%. Penutupan lahan gedung dapat menurunkan kerentanan lahan karena erosi berkurang yang disebabkan oleh tertutupnya tanah oleh lapisan kedap air. Namun dari aspek tata air, kondisi seperti gedung ini akan meningkatkan kerentanan tata air karena meningkatnya aliran permukaan dan berkurangnya kemampuan tanah menyerap air. Pemilihan data penutupan lahan sebagai input untuk menentukan kerentanan lahan sangat penting dan sensitif. Oleh karena itu, pada DAS Cisadane, pertanian lahan kering sebaiknya diklasifikasikan dalam tegalan dan permukiman pada daerah perkotaan diklasifikasikan sebagai gedung.
\end{abstract}

Kata Kunci: klasifikasi, kerentanan lahan, penutupan lahan

\footnotetext{
${ }^{1}$ Korespondensi Penulis: Balai Pelatihan dan Pengembangan Teknologi Pengelolaan Daerah Aliran Sungai Solo Email: ibpramono@yahoo.com
} 


\title{
84 Reklasifikasi Peta Penutupan Lahan untuk Meningkatkan Akurasi Kerentanan Lahan
}

\begin{abstract}
Land vulnerability is an important information to formulate land rehabilitation activities since it indicates the response of that particular land to erosion. It was determined by several factors such as slope, soil types, rainfall, and land cover. The land cover could be managed to maintain the land vulnerability. Inaccuracies of land cover classification would produce different vulnerabilities, which can cause miscalculation in land rehabilitation planning and implementation. This research is to adjust the existing land cover classification in order to detect land vulnerabilities. The analysis is done by comparing the classification of the existing land cover map with land cover criteria for land vulnerability analysis. The classification result then overlayed with land system map to determine the land vulnerability. The result of a study in Cisadane watershed shows that inaccuracy in determining unirrigated farming into shrub land or moor/open field could affect the shifting of vulnerable class to very vulnerable. Differences in determining plantations and unplanted estate areas with open field could also raise the extent of land vulnerability to $12.3 \%$. Settlement in an urban area that turned into buildings would reduce the level of land vulnerability to $2.1 \%$. Buildings could reduce the land vulnerability due to the impermeable layer would decrease erosion. However, from the hydrological point of view, the impermeable layers would increase the hydrological vulnerability due to the increased runoff and reduced ability to absorb water. Land cover data selection as input to determine the land vulnerability is very important and sensitive. For that reason, in the Cisadane Watershed, dryland farming should be classified as open field and settlement in urban areas should classify as buildings.
\end{abstract}

Keywords: classification, land vulnerability, land cover

\section{Pendahuluan}

Kerusakan Daerah Aliran Sungai (DAS) sebagai akibat erosi dan aliran permukaan telah terjadi sejak lama, tetapi sampai saat ini masih merupakan masalah yang belum dapat diselesaikan. Pada tahun 1984, Kementerian Pekerjaan Umum, Kementerian Kehutanan dan Kementerian Dalam Negeri menetapkan penanganan 22 DAS Prioritas melalui Surat Keputusan Bersama. Penanganan erosi ternyata belum dapat dilakukan dengan baik, karena tahun 2009 terbit Surat Keputusan Menteri Kehutanan mengenai DAS Prioritas melalui Keputusan Menteri Kehutanan No. 328/Menhut-II/2009 tentang Penetapan DAS Prioritas yang menetapkan 108 DAS Prioritas harus ditangani selama periode tahun 20102014 di seluruh Indonesia. Jumlah DAS Prioritas ini meningkat dibandingkan tahun 1984. Periode 2015-2019 ditetapkan 15 DAS prioritas (Peraturan Dirjen PDAS HL No 10, 2015), yaitu 6 DAS di Jawa dan sisanya di luar Jawa.

Perubahan penggunaan lahan merupakan salah satu faktor yang dapat menyebabkan suatu DAS mengalami kerusakan lingkungan (Ferreira, Samora-Arvela, \& Panagopoulos, 2016; Metzger, Rounsevell, Acosta-Michlik, Leemans, \& Schröter, 2006), sedangkan faktor manusia dapat menentukan apakah perubahan tersebut ke arah merusak atau lestari. Perubahan penggunaan lahan yang paling sering menyebabkan kerusakan lingkungan adalah berubahnya lahan hutan menjadi pertanian atau permukiman.

Salah satu penyebab perubahan lahan pertanian menjadi non-pertanian adalah sebagai akibat dari kebijakan pengembangan pusat pertumbuhan ekonomi, perdagangan, dan wisata sehingga mempercepat perkembangan lahan permukiman (Wibowo, Soeprobowati, \& Sudarno, 2015). Perubahan lahan menjadi permukiman tersebut biasanya berasal dari sawah (irigasi maupun tadah hujan), ladang, tegalan, dan perkebunan (Wibowo, Soeprobowati, \& Sudarno, 2015). Seperti halnya di Klaten, Jawa Tengah, perubahan penggunaan lahan dari sawah menjadi permukiman juga terjadi di Sukoharjo, Karanganyar dan Boyolali, sebagai akibat dari pembangunan wilayah yang sangat cepat (Anna, Priyana, \& S, 2014). Perubahan ini juga disebabkan karena tingginya harga lahan yang mengakibatkan petani menjual lahan mereka dan lebih memilih bekerja di luar sektor 
pertanian (Ruspendi, Hadi, \& Rusdiana, 2013). Perubahan penutupan lahan hutan menjadi lahan budidaya, permukiman, semak belukar atau terbuka berpotensi menjadi kritis (Kubangun, Haridjaja, \& Gandasasmita, 2016) karena penutupan yang sebelumnya rapat menjadi lebih terbuka.

Perubahan penutupan lahan yang berakibat menelantarkan lahan dapat meningkatkan atau menurunkan erosi (Mancino, Nolè, Salvati, \& Ferrara, 2016). Apabila lahan terlantar tersebut dapat berubah menjadi semak belukar atau hutan, tentu akan memberikan hasil erosi yang lebih rendah. Sebaliknya, apabila lahan terlantar tersebut berubah menjadi lebih terbuka, misalnya tegalan, maka erosi akan meningkat.

Secara umum, kerusakan lahan terjadi karena penutupan lahan tidak sesuai dengan faktor fisik lahan lainnya. Faktor fisik lahan lainnya dapat diperoleh dari sistem lahan yang dikembangkan oleh Badan Informasi Geospasial (BIG) melalui RePPProT. Unit satuan dalam sistem lahan mempertimbangkan antara lain: litologi, hidrologi, iklim, tanaman, penggunaan lahan, dan tanah (Poniman \& Lumban-Tobing, 2004).

Kerentanan suatu DAS adalah potensi permasalahan yang ada di dalam DAS yang kemudian menjadi ciri atau karakteristik dari DAS tersebut (Paimin, Sukresno, \& Purwanto, 2010). Kerentanan tersebut menunjukkan derajat kemudahan suatu lahan mengalami degradasi, yang disebabkan oleh faktor alami dan faktor manajemen. Faktor alami adalah sistem lahan, sedangkan faktor manajemen adalah penutupan lahan (Paimin, Pramono, Purwanto, \& Indrawati, 2012).

Respon lahan terhadap erosi dapat diperkirakan dengan cara menggabungkan peta penutupan lahan dan sistem lahan (Paimin, Pramono, Purwanto, \& Indrawati, 2012). Sistem lahan cenderung tidak terlalu banyak berubah dibandingkan dengan penutupan lahan, sehingga penutupan lahan merupakan faktor yang berpengaruh terhadap penentuan kerentanan lahan. Semakin terbuka suatu lahan atau semakin berbukit lahan tersebut, maka semakin tinggi tingkat kerentanan lahan tersebut terhadap erosi (Paimin, Pramono, Purwanto, \& Indrawati, 2012) .

Peta penutupan lahan saat ini dibuat oleh Direktorat Jenderal Planologi Kehutanan dan Tata Lingkungan/Ditjen PKTL (Direktorat Jenderal Planologi Kehutanan dan Tata Lingkungan, 2016). Peta tersebut dibuat berdasarkan beberapa citra, yaitu Landsat TM dan ETM+, SPOT, serta MODIS untuk beberapa tempat tertentu (Margono, Usman, Budiharto, \& Sugardiman, 2016). Terdapat 23 penggunaan lahan yang diperoleh melalui interpretasi secara manual dan diperbarui setiap tiga tahun sekali. Unit lahan terkecil yang diregister sebesar 6,25 ha pada skala 1:50.000 atau 25 ha pada skala 1:250.000 (Margono, Usman, Budiharto, \& Sugardiman, 2016).

\section{Metode Penelitian}

Lokasi kajian terletak di DAS Cisadane dengan luas 151.576 ha, yang meliputi Kabupaten Bogor (67\%), Kabupaten Tangerang (18,8\%), Kota Tangerang (5,6\%), Kabupaten Sukabumi (5,1\%), Kota Bogor (2,5\%), Kabupaten Tangerang Selatan, Lebak dan Kota Jakarta Barat yang masing-masing kurang dari $1 \%$ disajikan pada Gambar 1 . Secara geografis DAS Cisadane terletak pada 600,24' - 6047,3' LS dan 106028,8' - 106056,4' BT. Penelitian ini dilaksanakan sepanjang tahun 2016.

Bahan yang digunakan adalah peta penutupan lahan tahun 2015 dalam bentuk digital yang diterbitkan setiap tahun oleh Ditjen PKTL skala 1:250.000, peta sistem lahan yang diperoleh dari RePPProT yang diterbitkan oleh BIG pada tahun 1987 skala $1: 250.000$ dan citra DEM dari SRTM (Shuttle Radar Topography Mission) 1 Arc-Second Global dengan resolusi 30 meter yang di-download dari website USGS (www.earthexplorer.usgs.gov).

Peta penutupan lahan yang dikeluarkan oleh Ditjen PKTL terdiri dari 13 kelas penutupan lahan, keterangan untuk masing-masing penutupan lahan dijelaskan pada Tabel 


\section{Reklasifikasi Peta Penutupan Lahan untuk Meningkatkan Akurasi Kerentanan Lahan}

1. Selanjutnya, dengan menggunakan kriteria klasifikasi penentuan kerentanan lahan Paimin, Pramono, Purwanto, \& Indrawati (2012) penutupan lahan tersebut kemudian direklasifikasi menjadi lima kelas. Kelas yang semakin besar menunjukkan penutupan lahan tersebut semakin mudah tererosi.

Demikian juga dengan sistem lahan, peta RePPProT yang dikeluarkan oleh BIG pada DAS Cisadane terdiri dari 17 jenis dan dikelompokkan ke dalam lima kelas berdasarkan kemudahan untuk tererosi, yang menunjukkan bahwa makin besar kelasnya makin mudah tererosi (Paimin et al., 2012).

Analisis dilakukan dengan melakukan tumpang-susun peta penutupan lahan dengan peta sistem lahan untuk menentukan kelas kerentanan lahan terhadap erosi (Paimin et al., 2012). Penentuan kelas kerentanan lahan tersebut disajikan pada Tabel 2. Semakin tinggi nilai hubungan antara sistem lahan dan penutupan lahan menunjukkan semakin rentan lahan tersebut terhadap erosi. Diagram alir analisis kerentanan lahan disajikan pada Gambar 2.

Tabel 1. Penutupan Lahan Menurut BAPLAN Departemen Kehutanan Tahun 2001

\begin{tabular}{|c|c|}
\hline No. & Kelas \\
\hline 1. & $\begin{array}{l}\text { Hutan lahan ker } \\
\text { primer }\end{array}$ \\
\hline 2. & $\begin{array}{l}\text { Hutan lahan ker } \\
\text { sekunder }\end{array}$ \\
\hline 3. & Hutan tanaman \\
\hline 4. & Semak/belukar \\
\hline 5. & $\begin{array}{l}\text { Pertanian lahan } \\
\text { kering }\end{array}$ \\
\hline 6. & $\begin{array}{l}\text { Pertanian lahan } \\
\text { kering campur } \\
\text { semak }\end{array}$ \\
\hline 7. & Sawah \\
\hline 8. & Tambak \\
\hline 9. & Perkebunan \\
\hline
\end{tabular}

10. Permukiman

11. Tanah terbuka

12. Pertambangan Tanah terbuka yang digunakan untuk kegiatan pertambangan terbuka, openpit (batubara, timah, tembaga dll). Tambang tertutup seperti minyak, gas dll tidak dikelaskan tersendiri, kecuali mempunyai areal yang luas 


\begin{tabular}{lll}
\hline No. & \multicolumn{1}{c}{ Kelas } & \multicolumn{1}{c}{ Keterangan } \\
\hline & & sehingga dapat dibedakan dengan jelas pada citra \\
13. Tubuh air & $\begin{array}{l}\text { Semua kenampakan perairan, termasuk laut, sungai, danau, waduk, } \\
\text { terumbu karang dan lamun (lumpur pantai). Khusus kenampakan tambak } \\
\end{array}$ & di tepi pantai dimasukkan dalam pertanian lahan basah. \\
\hline
\end{tabular}

Sumber: Mahyuddin, Sugianto, \& Alvisyahrin, 2013

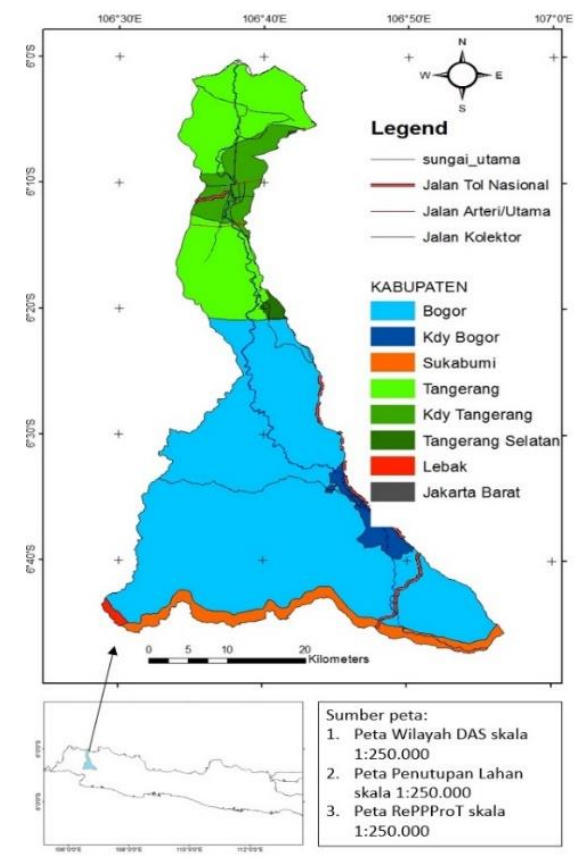

Gambar 1. Peta Lokasi DAS Cisadane

Tabel 2. Skala Kerentanan Lahan terhadap Erosi

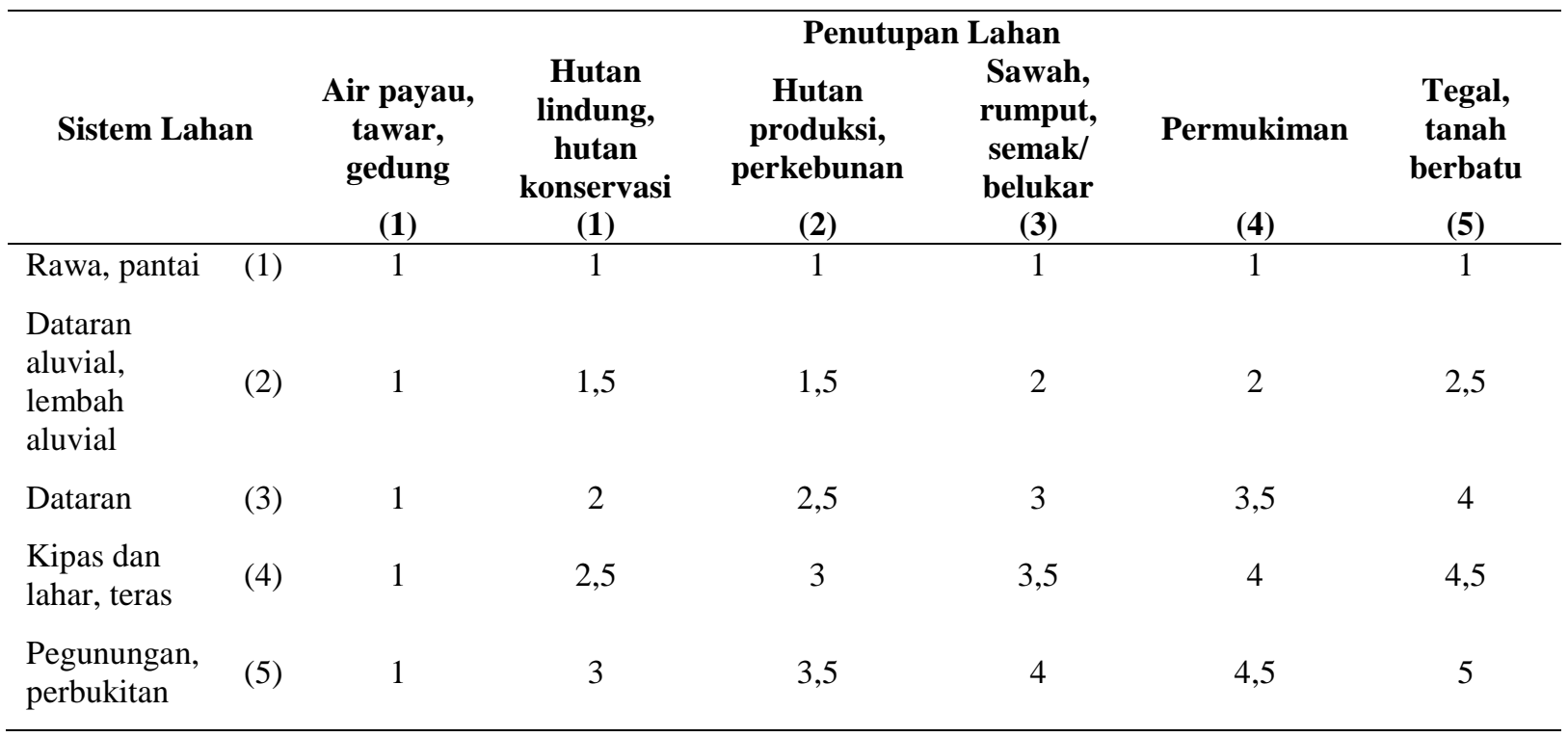

Sumber: Paimin, et al, 2012

Keterangan: angka dalam kurung merupakan skor parameter yang bersangkutan

$1=$ tidak rentan dan $5=$ sangat rentan 


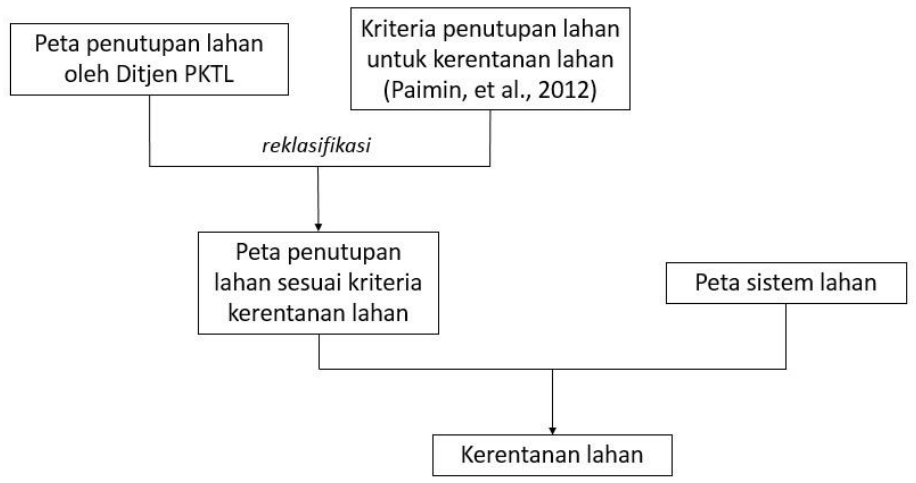

Sumber: Modifikasi dari Paimin, et al, 2012

\section{Gambar 2. Diagram Alir Analisis Kerentanan Lahan}

\section{Hasil dan Pembahasan}

Penyebaran penutupan lahan pada lokasi studi sesuai dengan klasifikasi penutupan lahan Ditjen PKTL disajikan pada Tabel 3. Tabel 3 memperlihatkan bahwa pertanian lahan kering adalah penutupan lahan yang paling banyak $(31,36 \%)$ terdapat di DAS Cisadane, dan diikuti dengan permukiman $(18,78 \%)$ dan sawah $(15,17 \%)$.

Pertanian lahan kering di daerah hulu (Kabupaten Bogor) dapat dideskripsikan sebagai berikut: tanaman yang umum dijumpai adalah jagung dan singkong, sedangkan pada beberapa tempat ditanami sayuran seperti cabai, berada pada lahan yang berlereng curam serta jarang menerapkan teknik konservasi tanah. Keadaan ini sering menjadi penyebab terjadinya erosi. Sawah juga banyak ditemukan pada lereng-lereng yang curam. Keadaan pertanian lahan kering dan sawah pada bagian hulu DAS Cisadane disajikan pada Gambar 3.

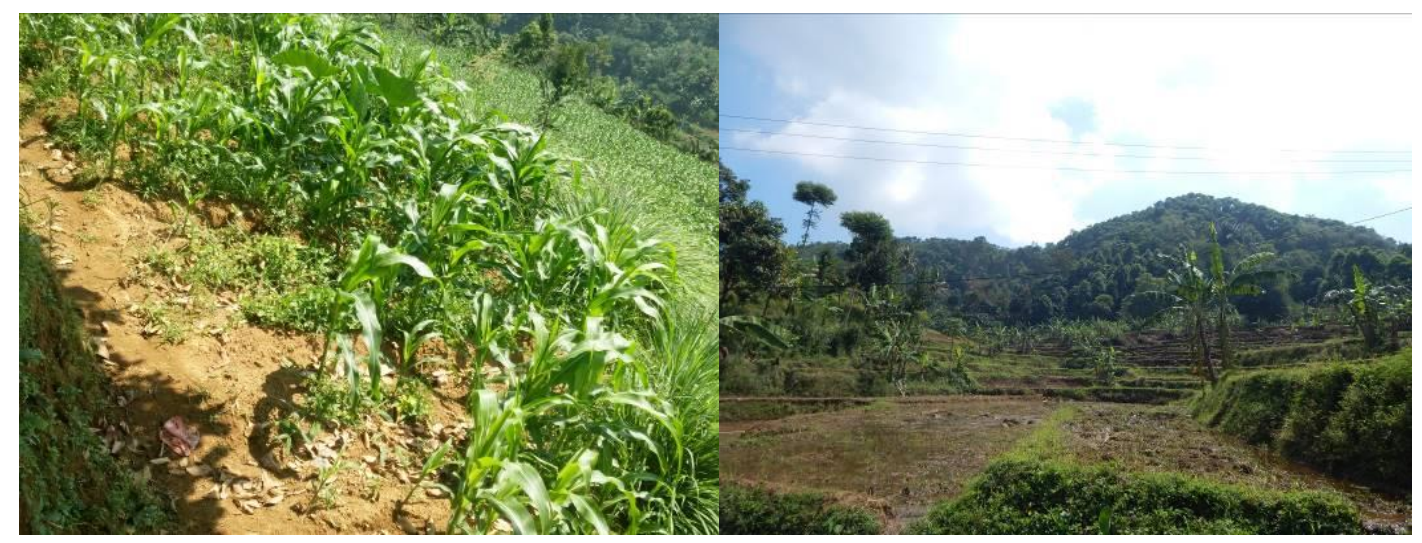

Sumber: Dokumentasi Pribadi, 2016

Gambar 3. Keadaan Pertanian Lahan Kering (Kiri) dan Sawah (Kanan) di Hulu DAS Cisadane 
Tabel 3. Penutupan Lahan pada DAS Cisadane sesuai Klasifikasi Ditjen PTKL

\begin{tabular}{lrr}
\hline \multicolumn{1}{c}{ Penutupan Lahan } & \multicolumn{1}{c}{ Luas } & \multicolumn{1}{c}{ (ha) } \\
\hline Pertanian lahan kering (Pt) & $47.529,50$ & 31,36 \\
Permukiman (Pm) & $28.464,82$ & 18,78 \\
Sawah (Sw) & $23.000,41$ & 15,17 \\
Pertanian lahan kering bercampur semak (Pc) & $17.171,20$ & 11,33 \\
Hutan lahan kering sekunder (Hs) & $9.939,59$ & 6,56 \\
Hutan tanaman (Ht) & $8.791,06$ & 5,8 \\
Hutan lahan kering primer (Hp) & $7.837,74$ & 5,17 \\
Tambak (Tm) & $3.296,69$ & 2,17 \\
Perkebunan (Pk) & $3.095,57$ & 2,04 \\
Bandara (Bdr) & $1.479,63$ & 0,98 \\
Tubuh air (A) & 941,15 & 0,62 \\
Lahan terbuka (T) & 17,62 & 0,01 \\
Pertambangan (Tb) & 11,66 & 0,01 \\
\hline TOTAL & $151.576,65$ & \\
\hline Sumber: Pengolahan
\end{tabular}

Sumber: Pengolahan Data dari Peta Penutupan Lahan Direktorat Jenderal Planologi

Kehutanan dan Tata Lingkungan, 2016

Seluruh jenis penutupan lahan pada Tabel 3 kemudian direklasifikasi sesuai dengan kriteria pada Tabel 2 sesuai dengan metode pada Gambar 2. Reklasifikasi kelas penutupan lahan tersebut dibuat berdasarkan pertimbangan kemampuan penutupan lahan tersebut dalam melindungi tanah terhadap erosi dan aliran permukaan. Pada penutupan lahan yang mirip, sebagai contoh hutan lahan kering primer dan hutan lahan kering sekunder, maka faktor utama yang membedakannya adalah kenampakan bekas tebangan (keterangan setiap kelas pada Tabel 1). Dengan demikian, hutan lahan kering primer dapat diklasifikasikan dalam hutan lindung atau hutan konservasi, sedangkan hutan lahan kering sekunder diklasifikasikan dalam hutan tanaman atau perkebunan. Hasil reklasifikasi penutupan lahan yang disesuaikan dengan Tabel 2 disajikan pada Tabel 4.

Tabel 4. Reklasifikasi Kelas Penutupan Lahan Ditjen PTKL dengan Kriteria Penutupan Lahan untuk Kerentanan Lahan

\begin{tabular}{ll}
\hline \multicolumn{1}{c}{ Ditjen PKTL } & \multicolumn{1}{c}{ Paimin et, al. (2012) } \\
\hline 1. Hutan lahan kering primer $(\mathrm{Hp})$ & b. Hutan lindung, hutan konservasi \\
2. Hutan lahan kering sekunder (Hs) & c. Hutan produksi, perkebunan \\
3. Hutan tanaman $(\mathrm{Ht})$ & c. Hutan produksi, perkebunan \\
4. Semak belukar (B) & d. Sawah, rumput, semak/ belukar \\
5. Pertanian lahan kering (Pt) & d. Sawah, rumput, semak/ belukar \\
& f. Tegal, tanah berbatu \\
6. Pertanian lahan kering bercampur semak (Pc) & d. Sawah, rumput, semak/ belukar \\
7. Sawah (Sw) & d. Sawah, rumput, semak/ belukar \\
8. Tambak (Tm) & a. Air payau, tawar, gedung \\
9. Perkebunan $(\mathrm{Pk})$ & c. Hutan produksi, perkebunan
\end{tabular}




\begin{tabular}{ll}
\hline \multicolumn{1}{c}{ Ditjen PKTL } & \multicolumn{1}{c}{ Paimin et, al. (2012) } \\
\hline 10. Permukiman $(\mathrm{Pm})$ & e. Permukiman \\
& a. Air payau, tawar, gedung \\
11. Tanah terbuka (T) & f. Tegal, tanah berbatu \\
12. Pertambangan (Tb) & f. Tegal, tanah berbatu \\
13. Tubuh air (A) & a. Air payau, tawar, gedung \\
\hline
\end{tabular}

Sumber: Analisis Data, 2016

Pertanian lahan kering bercampur semak dapat direklasifikasikan dalam sawah, rumput, semak/belukar (d) atau tegal, tanah berbatu (f). Berdasarkan definisi pada Tabel 1, maka pertanian lahan kering bercampur semak dapat direklasifikasikan dalam semak/belukar (d). Sebaliknya, pertanian lahan kering yang didefinisikan sebagai tegalan, kebun campuran dan ladang lebih sulit dalam klasifikasinya, karena kebun campuran lebih tertutup permukaannya dibandingkan dengan tegalan dan ladang. Tegalan dan ladang digolongkan dalam tegal dan tanah berbatu (f), sedangkan kebun campuran dapat digolongkan dalam sawah, rumput, semak/belukar (d).

Permukiman juga dapat direklasifikasikan dalam dua kelas klasifikasi, yaitu tetap sebagai permukiman (e), atau menjadi gedung (a). Apabila permukiman tersebut di daerah perkotaan, atau didominasi oleh bangunan gedung dan banyak mengalami kekedapan air, maka permukiman tersebut dapat direklasifikasikan dalam air payau, tawar, gedung (a).

Analisis citra dilakukan kembali hanya pada penutupan lahan yang dapat diklasifikasikan ke dalam dua penutupan lahan sesuai dengan Tabel 4, yaitu pertanian lahan kering dan permukiman. Penutupan lahan yang telah diklasifikasikan sebagai pertanian lahan kering yang lebih tertutup digabungkan dengan pertanian lahan kering bercampur semak. Pertanian lahan kering sendiri lebih mengarah pada tegalan. Permukiman juga dipisahkan menjadi permukiman dan bangunan/gedung. Kompleks pergudangan, perkantoran, dan pertokoan yang diklasifikasikan dalam permukiman dipisahkan dan diberi label gedung. Tabel 5 memperlihatkan perbedaan hasil interpretasi dengan peta penutupan lahan oleh Ditjen PKTL.

Tabel 5. Perbedaan Luas (Ha) dan Tingkat Kerentanan Penutupan Lahan Ditjen PTKL dan Hasil Interpretasi

\begin{tabular}{|c|c|c|c|c|}
\hline \multirow{2}{*}{$\begin{array}{l}\text { Kelas Kerentanan } \\
\text { Permukiman }\end{array}$} & \multirow{2}{*}{\multicolumn{2}{|c|}{$\begin{array}{c}\text { Ditjen PKTL } \\
\text { Pm }\end{array}$}} & \multicolumn{2}{|c|}{ Hasil interpretasi } \\
\hline & & & Pm & Gedung \\
\hline Tidak Rentan & & 245,0 & 178,9 & $1.061,6$ \\
\hline Sedikit Rentan & & $5.006,1$ & $4.701,4$ & - \\
\hline Agak Rentan & & - & - & - \\
\hline Rentan & & $22.806,2$ & $22.115,3$ & - \\
\hline Sangat Rentan & & 375,1 & 375,1 & - \\
\hline Jumlah & & $28.432,4$ & 27.370,8 & $1.061,6$ \\
\hline Pertanian lahan kering & $\mathbf{P t}$ & Pc & $\mathbf{P t}$ & Pc \\
\hline Tidak Rentan & - & 16,6 & - & 16,6 \\
\hline Sedikit Rentan & 757,8 & 303,8 & 757,8 & 303,8 \\
\hline Agak Rentan & - & $5.119,3$ & - & $6.271,2$ \\
\hline Pertanian lahan kering & $\mathbf{P t}$ & Pc & $\mathbf{P t}$ & Pc \\
\hline Rentan & $31.834,1$ & $12.495,0$ & $30.682,3$ & $14.462,5$ \\
\hline Sangat Rentan & $14.180,2$ & - & $12.212,7$ & - \\
\hline Jumlah & $17.934,7$ & 46.772 & $21.054,0$ & $43.652,7$ \\
\hline
\end{tabular}


Hasil interpretasi pada permukiman menunjukkan bahwa terdapat penutupan lahan yang dapat dikategorikan sebagai bangunan gedung. Pemisahan ini diperlukan karena air hujan yang turun pada gedung dan permukiman akan memberikan reaksi yang berbeda. Air hujan yang turun pada gedung tidak dapat meresap ke dalam tanah, sehingga tidak menyebabkan erosi, walaupun aliran permukaan yang terjadi lebih besar. Sebaliknya air hujan yang turun pada permukiman masih dapat menyebabkan erosi. Dengan demikian gedung dikeluarkan dari permukiman dan diklasifikasikan dalam (a) air payau, tawar, gedung (dapat dilihat pada Tabel 5). Perubahan permukiman menjadi gedung ini menyebabkan meningkatnya lahan yang tidak rentan (dari 0,9\% menjadi 4,4\%) dan menurunnya lahan yang rentan (dari 80,2\% menjadi 77,8\%) (dapat dilihat pada Tabel 5).

Pemisahan antara permukiman di daerah perkotaan yang berupa bangunan/gedung dan permukiman di daerah perdesaan selain untuk melihat tingkat kerentanan DAS juga digunakan untuk menentukan teknik konservasi air yang paling sesuai. Teknik konservasi air yang paling sesuai untuk permukiman pada daerah perkotaan adalah sumur resapan dan polder, sedangkan permukiman di daerah perdesaan dapat mengkombinasikan penanaman pohon dan pembuatan sumur resapan.

Pertanian lahan kering juga dapat direklasifikasi menjadi (d) sawah, rumput dan semak/belukar seperti pertanian lahan kering bercampur semak, atau menjadi (f) tegal, tanah berbatu. Agar pertanian lahan kering dapat diklasifikasikan menjadi tegal dan tanah berbatu, maka penutupan lahan berupa kebun campur dialihkan menjadi pertanian lahan kering bercampur semak.

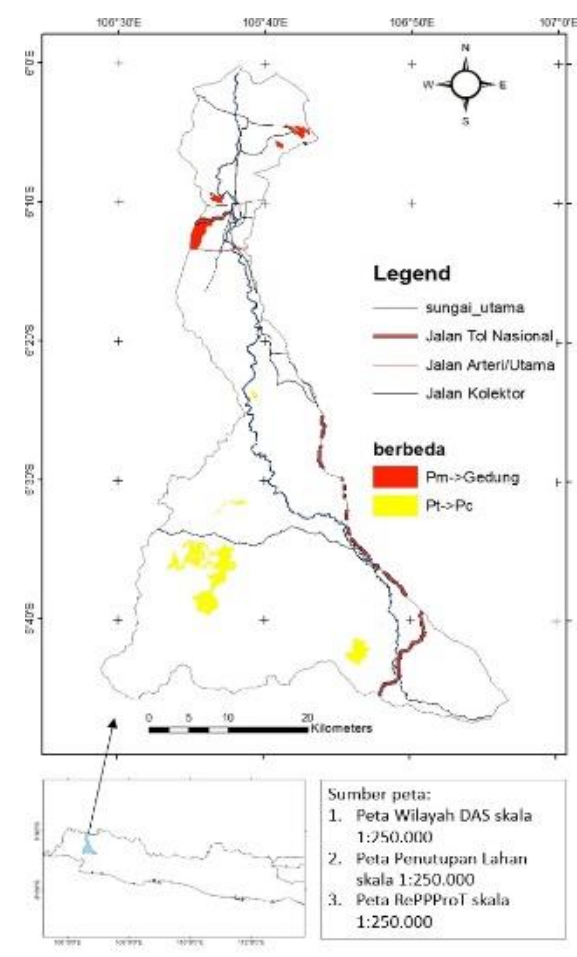

\section{Gambar 4. Lokasi Perubahan Penutupan Lahan dari Permukiman menjadi Gedung serta dari Pertanian Lahan Kering menjadi Pertanian Lahan Kering Bercampur Semak}

Hasil reinterpretasi pertanian lahan kering dan pertanian lahan kering bercampur semak yang disajikan pada Tabel 5 yang menunjukkan perubahan kelas kerentanan lahan pada DAS Cisadane. Apabila menggunakan penutupan lahan dari Ditjen PKTL luas lahan 


\section{2}

pertanian dan pertanian bercampur semak yang sangat rentan sebesar 21,9\% turun menjadi 18,9\% setelah lebih dari 3.000 ha pertanian lahan kering direklasifikasi menjadi pertanian lahan kering bercampur semak. Gambar 4 memperlihatkan lokasi perubahan permukiman yang direklasifikasi menjadi gedung dan pertanian lahan kering yang menjadi pertanian lahan kering bercampur semak. Secara keseluruhan penutupan lahan, kelas kerentanan di DAS Cisadane mengalami penurunan, yaitu kelas tidak rentan meningkat 0,66\% dan kelas sangat rentan berkurang 1,3\%. Tabel 6 dan Gambar 5 memperlihatkan perubahan tersebut.

Peningkatan luas lahan yang tidak rentan berasal dari berubahnya penutupan lahan permukiman menjadi gedung, karena gedung termasuk dalam penutupan lahan yang tidak membuat lahan rentan terhadap erosi. Gambar 5 memperlihatkan seluruh penutupan lahan yang berupa air payau, tawar dan gedung akan menghasilkan kelas tidak rentan untuk seluruh sistem lahan.

Sebaliknya pengurangan luas lahan yang sangat rentan menjadi rentan disebabkan karena berubahnya sebagian penutupan lahan pertanian lahan kering menjadi pertanian lahan kering bercampur semak. Oleh karena sebagian penutupan lahan pertanian lahan kering yang dikategorikan sebagai ladang direklasifikasi menjadi pertanian lahan kering bercampur semak, maka kelas kerentanannya juga bergeser dari sangat rentan menjadi rentan. Hal ini disebabkan karena pertanian lahan kering diklasifikasikan sebagai (f) tegalan, tanah berbatu dengan skor 5 , sehingga kelas kerentanan yang maksimum adalah 5 (Tabel 2). Pertanian lahan kering bercampur semak, diklasifikasikan sebagai (d) sawah, rumput dan semak/belukar dengan skor 3, sehingga kelas kerentanan yang maksimum adalah 4 (rentan).

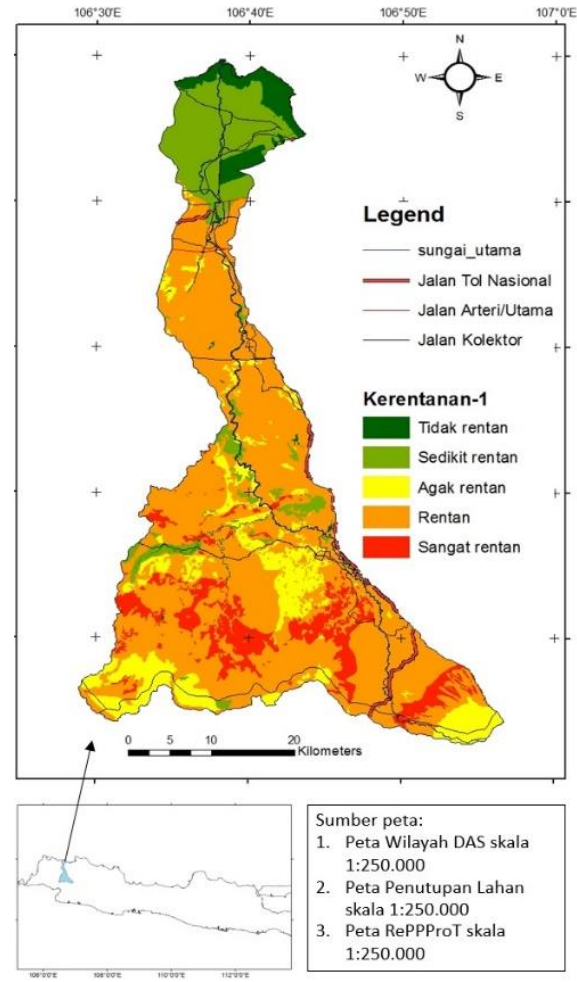

(a)

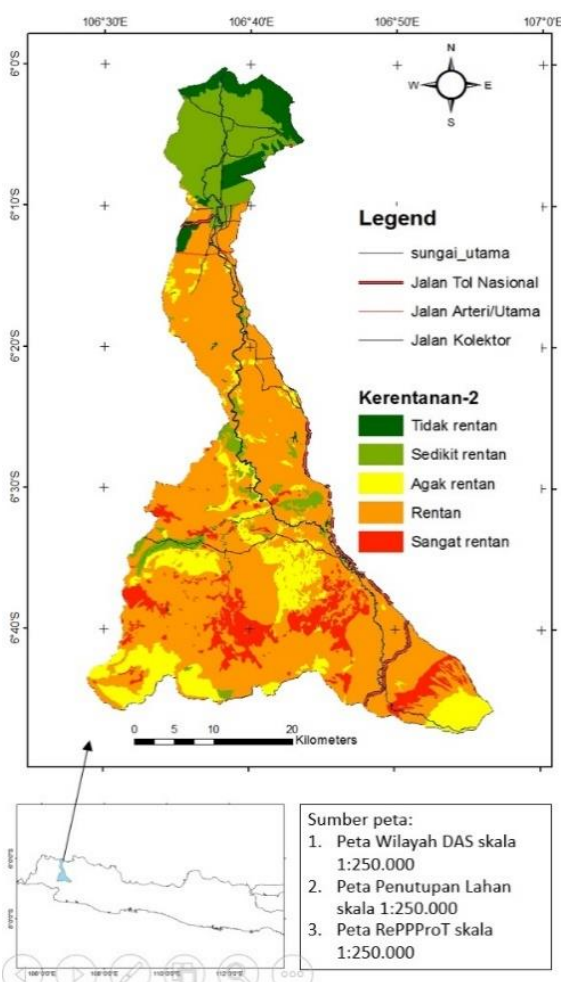

(b)

Gambar 5. Kelas Kerentanan Lahan terhadap Erosi pada DAS Cisadane (a) Menggunakan Peta Penutupan Lahan dari Ditjen PTKL dan (b) Menggunakan Peta Penutupan Lahan Hasil Re-interpretasi Penutupan Lahan Permukiman dan Pertanian Lahan Kering 
Tabel 6. Luas Kelas Kerentanan (Ha) pada DAS Cisadane

\begin{tabular}{lrrr}
\hline \multicolumn{1}{c}{$\begin{array}{c}\text { Kelas Kerentanan } \\
\text { Lahan }\end{array}$} & Ditjen PTKL & Hasil interpretasi & Beda \\
\hline Tidak rentan & $6.207,9$ & $7.203,4$ & 0,66 \\
Sedikit rentan & $19.480,3$ & $19.175,6$ & $-0,20$ \\
Agak rentan & $19.407,5$ & $20.559,4$ & 0,76 \\
Rentan & $91.900,1$ & $92.024,9$ & 0,08 \\
Sangat rentan & $14.580,9$ & $12.613,3$ & $-1,30$ \\
Total & $\mathbf{1 5 1 . 6 7 6 , 6}$ & $\mathbf{1 5 1 . 6 7 6 , 6}$ & \\
\hline
\end{tabular}

Sumber: Analisis Data, 2016

Tabel 6 dan Gambar 5 memperlihatkan bahwa perubahan penutupan lahan akan mempengaruhi penentuan kelas kerentanan lahan terhadap erosi, karena kerentanan lahan terhadap erosi merupakan salah satu dari tipologi DAS (Paimin et al., 2012), maka penutupan lahan yang relatif lebih dinamis dari sistem lahan menjadi penentu tingkat kerentanan lahan tersebut.

Tingkat kerentanan yang berubah tersebut akan berimplikasi pada status DAS Cisadane. Semakin luas lahan yang sangat rentan terhadap erosi, akan menjadikan DAS Cisadane sebagai salah satu DAS yang diprioritaskan untuk ditangani. Sebaliknya, berkurangnya luas lahan yang sangat rentan terhadap erosi menunjukkan bahwa DAS Cisadane membaik.

\section{Kesimpulan}

Pergeseran tingkat kerentanan sebagai akibat penyesuaian penutupan lahan menunjukkan bahwa penentuan penutupan lahan pada kelas yang paling tepat merupakan hal yang sangat penting dan sensitif. Kesalahan dalam menentukan penutupan lahan dapat menimbulkan perbedaan kerentanan suatu DAS. Pengecekan di lapangan terutama untuk pertanian lahan kering serta pertanian lahan kering bercampur semak sangat diperlukan untuk mengetahui keadaan penutupan lahan tersebut.

Studi yang dilakukan di DAS Cisadane menunjukkan perlu dilakukannya reklasifikasi penutupan lahan. Pertanian lahan kering disarankan hanya untuk tegalan dan ladang, sedangkan kebun campur dimasukkan dalam pertanian lahan kering bercampur semak. Dengan demikian pertanian lahan kering dapat sesuai dengan kriteria tegalan dan tanah berbatu.

Permukiman juga perlu dipisahkan antara permukiman pada daerah perkotaan dan perdesaan. Permukiman di perkotaan direklasifikasi menjadi gedung karena hampir seluruh permukaan tanahnya sudah tertutup aspal dan semen sehingga potensi erosinya sudah sangat kecil. Permukiman di perdesaan tetap diklasifikasikan sebagai permukiman karena masih ada permukaan tanah yang terbuka, serta memungkinkan terjadinya erosi.

\section{Daftar Pustaka}

Anna, A. N., Priyana, Y., \& S, A. A. (2014). Model Simulasi Luapan Banjir Sungai Bengawan Solo untuk Optimalisasi Kegiatan Tanggap Darurat Bencana Banjir. Forum Geografi, 28(1), 21-34. Retrieved from https://publikasiilmiah.ums.ac.id/handle/11617/4798.

Direktorat Jenderal Planologi Kehutanan dan Tata Lingkungan. (2016). Peta Penutupan Lahan. Retrieved from http://webgis.menlhk.go.id:8080/pl/pl.htm.

Ferreira, V., Samora-Arvela, A., \& Panagopoulos, T. (2016). Soil erosion vulnerability under scenarios of climate land-use changes after the development of a large reservoir in a semi-arid area. Journal of Environmental 


\section{Reklasifikasi Peta Penutupan Lahan untuk Meningkatkan Akurasi Kerentanan Lahan}

Planning and Management, 59(7), 1238-1256. doi:10.1080/09640568.2015.1066667.

Kementerian Kehutanan Republik Indonesia. (2009). Keputusan Menteri Kehutanan No. 328/Menhut-II/2009 tentang Penetapan Daerah Aliran Sungai (DAS) Prioritas Dalam Rangka Rencana Pembangunan Jangka Menengah (RPJM) Tahun 2010-2014. Jakarta.

Kubangun, S. H., Haridjaja, O., \& Gandasasmita, K. (2016). Model perubahan penutupan/penggunaan lahan untuk identifikasi lahan kritis di Kabupaten Bogor, Kabupaten Cianjur, dan Kabupaten Sukabumi. Majalah Ilmiah Globe, 18(1), 21-32. Retrieved from http://jurnal.big.go.id/index.php/GL/article/view/391.

Mahyuddin, Sugianto, \& Alvisyahrin, T. (2013). Analisis Penutupan Lahan Kawasan Hutan pada Daerah Aliran Sungai Krueng Aceh Pra dan Pasca Tsunami. Jurnal Manajemen Sumberdaya Lahan, 2(3), 296-303. Retrieved from http://www.jurnal.unsyiah.ac.id/MSDL/article/view/2197/2155.

Mancino, G., Nolè, A., Salvati, L., \& Ferrara, A. (2016). In-between Forest Expansion and Cropland Decline: A Revised USLE Model for Soil Erosion Risk Under Land-Use Change in a Mediterranean Region. Ecological Indicators, 71, 544-550. doi:10.1016/j.ecolind.2016.07.040.

Margono, B. A., Usman, A. B., Budiharto, \& Sugardiman, R. A. (2016). Indonesia's Forest Resource Monitoring. Indonesian Journal of Geography, 48(1), 7-20. $\quad$ Retrieved from https://jurnal.ugm.ac.id/ijg/article/view/12496.

Metzger, M. J., Rounsevell, M. D. A., Acosta-Michlik, L., Leemans, R., \& Schröter, D. (2006). The Vulnerability of Ecosystem Services to Land Use Change. Agriculture, Ecosystems and Environment, 114(1), 69-85. doi:10.1016/j.agee.2005.11.025.

Paimin, P., Sukresno, S., \& Purwanto, P. (2010). Sidik Cepat Degradasi Dub DAS. (A. N. Ginting, Ed.) (2nd ed.). Bogor: Pusat Penelitian dan Pengembangan Konservasi dan Rehabilitasi. Retrieved from http://www.forda-mof.org/files/Sidik_Cepat_Degradasi_SubDAS.pdf.

Paimin, Pramono, I. B., Purwanto, \& Indrawati, D. R. (2012). Sistem Perencanaan Pengelolaan Daerah Aliran Sungai. (H. Santoso \& Pratiwi, Eds.). Bogor: Pusat Litbang Konservasi dan Rehabilitasi.

Poniman, A., \& Lumban-Tobing, P. (2004). Developing the National Land Resource Database for Supporting Spatial Land Use Planning Developing the National Land Resource Database for Supporting Spatial Land Use Planning. In 3rd FIG Regional Conference (pp. 1-11).

Ruspendi, D., Hadi, S., \& Rusdiana, O. (2013). Kajian Perubahan Penutupan Lahan pada DAS Ciliwung Hulu dengan Pendekatan Spasial Dinamik. Jurnal Lanskap Indonesia, 5(2), 1-5. Retrieved from http://journal.ipb.ac.id/index.php/jli/issue/view/1509.

Wibowo, A., Soeprobowati, T. R., \& Sudarno. (2015). Laju Erosi dan Sedimentasi Daerah Aliran Sungai Rawa Jombor dengan Model USLE dan SDR untuk Pengelolaan Danau Berkelanjutan. Indonesian Journal of Conservation, 4(1), 16-27. Retrieved from https://journal.unnes.ac.id/nju/index.php/ijc/article/view/5154. 